\title{
Familial Cases of Endomyocardial Fibrosis in Uganda
}

\author{
ASHVIN K. PATEL, JOHN L. ZIEGLER, PAUL G. D'ARBELA, KRISHNA SOMERS
}

British Medical fournal, 1971, 4, 331-334

\section{Summary}

This report describes nine cases of endomyocardial fibrosis occurring in four families. All patients came from Rwanda or South-western Uganda, and five had tropical splenomegaly syndrome as well. It seems likely that genetic as well as environmental factors are operative in the aetiology of endomyocardial fibrosis.

\section{Introduction}

Considerable knowledge of endomyocardial fibrosis has been accumulated since its recognition as a clinicopathological entity by Davies (1948) and Ball et al. (1954). In the last decade a series of papers have appeared from Kampala advancing knowledge of pathological aspects (Connor et al., 1967, 1968), haemodynamic disturbances (Shillingford and Somers, 1961; Fowler and Somers, 1968; Somers et al., 1968a), and clinical diagnosis (Somers et al., 1968b; Somers and Fowler 1968). Various aetiological factors have been postulated, but the cause of endomyocardial fibrosis still remains unknown. The main areas of endemicity seem to be Uganda and Nigeria though cases have been reported from other tropical and non-tropical countries (cited by van der Geld et al., 1966). In Uganda endomyocardial fibrosis affects predominantly immigrants from Rwanda and Burundi (Somers and D'Arbela, 1964) though indigenous Ugandans, particularly those from the south-west districts, are also susceptible.

This report describes cases of endomyocardial fibrosis occurring in four families. In two families both the mother and the child had endomyocardial fibrosis. A brother and a sister were affected in the third family. Three cases and possibly a fourth were found among a Rwandan kindred, most of whom had splenomegaly attributed to tropical splenomegaly syndrome (Ziegler et al., 1970). Possible familial factors in the aetiology of endomyocardial fibrosis are discussed.

\section{Case Reports}

The cases reported below were seen and evaluated in the cardiology division of Mulago Hospital. These patients were referred either from up-country hospitals or from other departments in the hospital. The four cases reported from family D were under treatment for tropical splenomegaly syndrome and were found to have cardiac murmurs on routine examination. The diagnosis of endomyocardial fibrosis was based in all patients on a combination of the clinical features (Somers et al., $1968 \mathrm{~b}$; Somers and Fowler, 1968) and the finding of characteristic angiocardiographic and catheterization data as previously described (Cockshott et al., 1967; Somers et al., 1968a, 1971).

Makerere University and Mulago Hospital, and the Uganda Cancer Institute, P.O. Box 7072, Kampala, Uganda

ASHVIN K. PATEL, M.B., CH.B., M.MED., formerly Senior Medical Registrar (Present address: Veterans Administration Hospital, Madison, Wisconsin 53705, U.S.A.)

JOHN L. ZIEGLER, M.D., Director, Lymphoma Treatment Centre

JOHN L. ZIEGLER, M.D., Director, Lymphoma Treatment Centre

PAUL G. D'ARBELA, M.R.C.P.(LOND., ED.), Senior Lecturer in Medicine
KRISHNA SOMERS, F.R.C.P., D.C.H., Clinical Professor of Medicine, Chief of the Division of Cardiology
FAMILY A

Case A1.-A 35-year-old Burundaise woman was first admitted to hospital in December 1967 with swelling of the legs and abdomen, progressive effort dyspnoea, and a dry non-productive cough of three months' duration. She came to Uganda from Burundi at an early age. She had five children, all of whom were born in Uganda. On examination she seemed ill and dyspnoeic, with facial puffiness, prominent eyes, and mild ankle oedema. The pulse rate was 108 per minute, blood pressure $100 / 80 \mathrm{~mm} \mathrm{Hg}$, and the jugular venous pressure was raised $10 \mathrm{~cm}$. The apex beat was located in the fifth intercostal space within the midclavicular line. A grade $3 / 6$ early mitral systolic murmur was heard which radiated a short distance towards the axilla. A pansystolic murmur heard over the tricuspid area increased in intensity on inspiration. The pulmonic second sound was moderately accentuated. Coarse, bilateral crepitations were heard over the lung fields, and a pleural effusion was detected on the right side. The liver was enlarged $9 \mathrm{~cm}$ below the right costal margin, and ascites was present. The electrocardiogram showed a low voltage and $\mathrm{P}$ mitrale. The chest radiograph showed cardiomegaly with a prominent left atrium. Pulmonary hypertensive changes were present in the lung fields. There was also a right-sided pleural effusion. Cardiac catheterization with angiocardiography was performed (see Table). The left ventricular angiocardiogram showed apical deformity and mitral regurgitation. In the right ventricle the apex was flattened and a free tricuspid regurgitation with a large right atrium was present.

Case A2.-A 6-year-old daughter of Case A1 gave a history of exertional dyspnoea and precordial discomfort of four months' duration. There was no history of rheumatic fever. On examination she was seen to be a well-nourished girl with prominence of both eyes. Her pulse rate was 120 . Jugular venous pressure was raised $6 \mathrm{~cm}$. The apex beat was a slight heave and palpable in the fifth intercostal space outside the midclavicular line. A short early systolic murmur with a third heart sound was heard at the mitral area. A palpable right ventricular outflow heave was felt in the left upper parasternal region. The lungs on auscultation were clear. The liver was enlarged $4 \mathrm{~cm}$ below the costal margin. The electrocardiogram showed sinus tachycardia, $\mathbf{P}$ mitrale, and right axis deviation with QRS axis of $+100^{\circ}$ in the frontal plane. The chest radiograph showed a large, rounded cardiac silhouette with an enlarged right atrium and right ventricular infundibular bulge and a very prominent left atrium. Cardiac catheterization data are summarized in the Table. A left ventricular angiocardiogram showed a rounded apex with free mitral regurgitation and a large left atrium. The right ventricular angiocardiogram showed obliteration of the apex, a dilated rounded infundibulum, and tricuspid regurgitation.

\section{FAMILY B}

Case B1.-A 30-year-old Rwandan woman had lived in Uganda for 20 years. She was first admitted to Mulago Hospital in May 1966 when she gave a year's history of cough with blood-stained sputum, exertional dyspnoea, orthopnoea, and swelling of the legs. She had three children: the first died as an infant, and the others were aged 9 and 14 years. Physical examination showed mild jaundice, minimal ankle oedema, and gross ascites. The pulse was of low volume, regular, and the blood pressure was 100/70. Jugular venous pressure was grossly raised. The apex beat was unremarkable. A short systolic murmur and a third heart sound were heard at the apex. The lungs were clear. The liver was enlarged $4 \mathrm{~cm}$ and the spleen $5 \mathrm{~cm}$ below the costal margins. The electrocardiogram showed low voltage, $P$ mitrale, and $S-T$ segment depression in leads V2 and V3. The chest radiograph showed cardiomegaly with an enlarged right atrium and a prominent infundibular bulge on the left heart border. Liver biopsy showed Kupffer cell hyperplasia with sinusoidal lymphocytic infiltration typical of tropical splenomegaly syndrome (Marsden et al., 1965). Cardiac catheterization with angiocardiography showed findings 
consistent with biventricular endomyocardial fibrosis, predominantly affecting the right ventricle (see Table).

Case B2.-The 14-year-old son of Case B1 presented with effort dyspnoea, palpitations, and swelling of the eyes for three years. He was a well-nourished child with prominent eyes. His pulse was 84 . Jugular venous pressure was raised $5 \mathrm{~cm}$. The apex beat was quiet. Prominent pulsation was felt over the right ventricular outflow tract. A loud third heart sound was heard over the precordium. The spleen was enlarged $4 \mathrm{~cm}$ below the costal margin. The electrocardiogram showed a QRS axis of $+70^{\circ}$ with $\mathrm{P}$ pulmonale, and $S-T$ segment depression with $T$-wave inversion in Vl-V4. The chest radiograph showed cardiomegaly with an enlarged right atrium and right ventricular infundibular bulge. Liver biospy showed sinusoidal lymphocytosis. Cardiac catheterization and angiocardiography confirmed a diagnosis of severe right ventricular endomyocardial fibrosis. The left ventricle seemed normal (see Table).

\section{COMMENTS ON FAMILIES A AND B}

In both families the mother and the child had endomyocardial fibrosis proved by cardiac catheterization and angiocardiography. Both the mothers had migrated to Uganda from Rwanda at an early age, whereas their children were born and raised in Uganda. In addition, both mother and child of family B had associated tropical splenomegaly syndrome confirmed on liver biopsy.

\section{FAMILY C}

Case C1.-A 15-year-old Nyankole boy presented with palpitations, effort dyspnoea, cough, and swelling of the abdomen for one year. His parents had migrated from Ankole to Mengo, where he was born. Of 12 children in the family only five survived and seven had died of various illness. He was a thin boy with mild ankle oedema. His pulse rate was 110 , blood pressure $100 / 60$, and the jugular venous pressure was raised. A prominent left upper parasternal heave was present. A soft early systolic murmur and a third heart sound were heard at the mitral area. The liver was enlarged $6 \mathrm{~cm}$ and the spleen $4 \mathrm{~cm}$ below the costal margins, and moderate ascites was present. The chest radiograph showed cardiomegaly with an enlarged right atrium and prominent infundibular bulge at the left heart border. An electrocardiogram showed low voltage and atrial fibrillation. A diagnosis of severe biventricular endomyocardial fibrosis was confirmed on cardiac catheterization and angiocardiography (see Table).

Case C2.-The sister of Case $\mathrm{C1}$, aged 23, gave a history of shortness of breath on exertion of four months' duration followed by swelling of the legs and abdomen. She was born in Ankole and came to Mengo as a child. On examination she had mild jaundice. The jugular venous pressure was raised $10 \mathrm{~cm}$. The apical impulse was felt in the fifth intercostal space $3 \mathrm{~cm}$ outside the midclavicular line. A left upper parasternal heave was also palpable. A short systolic murmur was heard at the apex. The pulmonic second sound was accentuated. The liver was enlarged $5 \mathrm{~cm}$ and the spleen $7 \mathrm{~cm}$ below the costal margins. Chest radiograph showed an enlarged heart with pulmonary congestion. The electrocardiogram showed low voltage and low or biphasic $\mathrm{T}$ waves. A diagnosis of biven- tricular endomyocardial fibrosis severely affecting the left ventricle was confirmed on cardiac catheterization and angiocardiography (see Table).

\section{COMMENTS ON FAMILY C}

In this particular family a brother and sister had endomyocardial fibrosis, three other siblings were well, and seven had died of unknown causes. It is possible that some of the siblings might have died of endomyocardial fibrosis.

\section{FAMILY D}

Case D1.-A 35-year-old Rwandan woman was admitted with a history of cough and shortness of breath for three weeks. She was born in Rwanda and had migrated to Uganda as a young child. Physical examination showed grossly raised jugular venous pressure, a pulse rate of 80 , and blood pressure of $110 / 80$. A short systolic murmur grade 3/6 was heard at the mitral area with a third heart sound. The pulmonic second sound was accentuated. A right pleural effusion was present and bilateral crepitations were heard in the chest. The liver was enlarged $7 \mathrm{~cm}$ and the spleen $4 \mathrm{~cm}$ below the costal margins, and ascites was present. A chest film showed cardiomegaly with pulmonary congestion and a right pleural effusion. The electrocardiogram showed low voltage, $\mathrm{P}$ mitrale, and S-T scgment depression in the lateral chest leads. Angiocardiugraphy of the left ventricle showed a "cupped" apical deformity and small mitral regurgitant flow. A right ventricular angiocardiogram showed a large cavity with tricuspid regurgitation. There was minimal apical flattening and septal crenations were preserved. The findings were consistent with severe endomyocardial fibrosis of the left ventricle with pulmonary hypertension and right ventricular hypertrophy (see Table).

Case D2.-A 35-year-old Rwandan man who had migrated to Uganda 25 years ago was first seen in 1968. On a routine examination he was found to have an enlarged liver and spleen, and a grade $3 / 6$ systolic murmur was heard at the left sternal edge. A chest film showed a slightly enlarged heart with prominent pulmonary veins. A liver biopsy showed Kupffer cell hyperplasia and sinusoidal lymphocytosis. He was readmitted in July 1969 with congestive cardiac failure. Jugular venous pressure was raised $5 \mathrm{~cm}$. A short systolic murmur grade 2-3/6 and a third heart sound were heard at the mitral area. A grade $3 / 6$ regurgitant murmur, increasing in inspiration, was also heard over the tricuspid area. A chest film showed cardiomegaly with pulmonary congestion and a small pleural effusion. Cardiac catheterization and angiocardiographic findings were consistent with posterior mitral valve leaflet endomyocardial fibrosis (see Table).

Case D3.-A 10-year-old Rwandan girl was admitted to hospital in February 1971 for evaluation of a systolic murmur which was first heard in December 1968. She complained of shortness of breath on severe exertion only. She had bilateral deformities of the feet from old poliomyelitis. The pulse rate was 70 and blood pressure $100 / 70$. Jugular venous pressure was not raised. The apex beat was felt just outside the midclavicular line and a grade 2/6 short systolic murmur was heard at the mitral area. The lung fields were clear. The spleen was enlarged $2 \mathrm{~cm}$ below the costal

Haemodynamic and Angiocardiographic Findings in Familial Cases of Endomyocardial Fibrosis

\begin{tabular}{|c|c|c|c|c|c|c|c|c|c|c|}
\hline \multirow{3}{*}{ Case } & \multirow{3}{*}{ Age } & \multirow{3}{*}{ Sex } & \multicolumn{6}{|c|}{ Pressure (mm Hg) } & \multirow{2}{*}{\multicolumn{2}{|c|}{ Angiocardiography }} \\
\hline & & & \multirow{2}{*}{$\underset{\text { (mean) }}{\text { P.C. (W.) }}$} & \multirow{2}{*}{ P.A. (S./D., mean) } & \multirow{2}{*}{ R.V. (S/D., mean) } & \multirow{2}{*}{$\underset{\text { (mean) }}{\text { R.A. }}$} & \multirow{2}{*}{ L.V. (S/D., mean) } & \multirow{2}{*}{ Aorta (S./D., mean) } & & \\
\hline & & & & & & & & & L.V. E.M.F. & R.V. E.M.F. \\
\hline $\begin{array}{l}\text { A1 } \\
\text { A2 } \\
\text { B1 } \\
\text { B2 } \\
\text { C1 } \\
\text { C2 } \\
\text { D1 } \\
\text { D2 } \\
\text { D3 } \\
\text { D4 }\end{array}$ & $\begin{array}{l}35 \\
6 \\
30 \\
14 \\
15 \\
23 \\
35 \\
35 \\
10 \\
10\end{array}$ & $\begin{array}{l}\text { F. } \\
\text { F. } \\
\text { F. } \\
\text { M. } \\
\text { M. } \\
\text { F. } \\
\text { F. } \\
\text { M. } \\
\text { F. } \\
\text { F. }\end{array}$ & $\begin{array}{r}40 \\
30 \\
11 \\
10 \\
19 \\
32 \\
37 \\
16 \\
12 \\
6\end{array}$ & $\begin{array}{l}105 / 46,65 \\
56 / 28,41 \\
27 / 13,20 \\
30 / 12,19 \\
26 / 20,23 \\
64 / 30,45 \\
65 / 31,45 \\
41 / 20,26 \\
26 / 11,17 \\
34 / 18,24\end{array}$ & $\begin{array}{l}101 / 17,47 \\
59 / 17,32 \\
28 / 11,16 \\
30 / 13,16 \\
28 / 19,21 \\
56 / 17,27 \\
61 / 13,27 \\
36 / 6,14 \\
29 / 9,14 \\
35 / 5,17\end{array}$ & $\begin{array}{r}17 \\
11 \\
11 \\
9 \\
19 \\
14 \\
14 \\
5 \\
8 \\
4\end{array}$ & $\begin{array}{r}127 / 26,70 \\
112 / 34,50 \\
115 / 16,52 \\
119 / 15,50 \\
117 / 15,50 \\
97 / 23,42 \\
102 / 29,50 \\
115 / 30,47 \\
118 / 18,50 \\
104 / 8,45\end{array}$ & $\begin{array}{r}121 / 86,98 \\
109 / 72,87 \\
116 / 66,88 \\
109 / 69,86 \\
116 / 77,90 \\
96 / 68,77 \\
113 / 69,86 \\
112 / 75,90 \\
140 / 83,100 \\
98 / 68,80\end{array}$ & $\begin{array}{l}+ \\
+ \\
+ \\
0 \\
+ \\
+ \\
+ \\
+ \\
+ \\
0\end{array}$ & $\begin{array}{l}+ \\
+ \\
+ \\
+ \\
+ \\
+ \\
+ \\
0 \\
+ \\
+ \\
0\end{array}$ \\
\hline
\end{tabular}
P.C. $($ W. $)=$ Pulmonary capillary wedge. P.A. $=$ Pulmonary artery. R.V. $=$ Right ventricle. R.A. $=$ Right atrium. L.V. $=$ Left ventricle. S./D. $=$ Systolic pressure/diastolic
pressure. $+=$ Present. $(+)=$ Probably present. $0=$ Absent. L.V. E.M.F. $=$ Left ventricular endomyocardial fibrosis. R.V. E.M.F. $=$ Right ventricular endomyocardial pressure. 
margin. Chest radiograph showed a prominent main pulmonary artery and no other abnormality. The electrocardiogram showed $\mathrm{T}$-wave inversion across the chest leads. The angiocardiogram showed a blunting of the right ventricular apex. The left atrium was enlarged but the presence of mitral incompetence could not be ascertained as the catheter tip pointed into the left atrium. The findings were consistent with early endomyocardial fibrosis involving the right ventricular apex and posterior mitral valve leaflet.

Case D4.-A 10-year-old Rwandan girl was referred to hospital in September 1967 for splenomegaly and epistaxis. She was found to have tropical splenomegaly syndrome, and a splenectomy was performed. On subsequent examination she was found to have a systolic murmur, and was referred to the cardiac clinic for further evaluation. She had no complaints referable to cardiac failure. The pulse rate was 80 and the blood pressure 100/70. Examination of the heart showed a grade $2 / 6$ apical systolic murmur which radiated faintly to the axilla. An electrocardiogram was normal, and a chest film showed borderline cardiac enlargement. Cardiac catheterization and angiocardiography were normal and no cardiac diagnosis could be established.

\section{COMMENTS ON FAMILY D}

Cases D3 and D4 are sisters, Case D1 is their great aunt, and Case D2 is a nephew of D1 by marriage. These patients were selected on the basis of abnormal cardiac findings after routine physical examination of 23 members of a Rwandan kindred living in Mengo District. Tropical splenomegaly syndrome was diagnosed by liver biopsy in 12 family members and clinically in an additional 10 members. Three members with tropical splenomegaly syndrome had definite evidence of endomyocardial fibrosis (Cases D1, D2, and D3) and a fourth had minimal cardiac abnormalities without diagnostic features. All patients with endomyocardial fibrosis were born in Uganda though their parents had originally come from Rwanda.

\section{Discussion}

The aetiology of endomyocardial fibrosis remains speculative, and such factors as diet, viral infectiois, parasitic disease, and immunological mechanisms have been implicated in clinical, pathological, serological, and epidemiological studies (van der Geld et al., 1966; Connor et al., 1967, 1968; Shaper et al., 1968a; Crawford et al., 1970). An increased prevalence of endomyocardial fibrosis in Uganda has been noted among immigrants from Rwanda, Burundi, and South-west Uganda (Somers and D'Arbela, 1964; Shaper et al., 1968b). The aetiological significance of this observation is uncertain, though it has been suggested that low socioeconomic status, malnutrition, or altered immunological responses may be responsible for the increased susceptibility of this group (van der Geld et al., 1966; Shaper et al., 1968a).

To our knowledge the present study is the first report of the familial occurrance of endomyocardial fibrosis in the tropics. Our cases were from four families of Rwandan or related tribal origin. They were either born in Mengo District or had migrated to the area at an early age. There were two families (A and B) in which endomyocardial fibrosis was diagnosed in both parent and child, and one family (C) with two siblings affected. Members of a fourth kindred (D), many of whom suffer from tropical splenomegaly syndrome, were investigated, and three cases of endomyocardial fibrosis were diagnosed. An additional member of this family (Case D4) was found to have minima; cardiac abnormalities, but a diagnosis of endomyocardiai fibrosis could not be established.

Detailed epidemiological studies of endomyocardial fibrosis are hampered by difficulty in the diagnosis of the condition in its early stages. By the time symptoms and signs of cardiac failure are present the disease is usually far advanced. Early lesions are recognizable at necropsy, however (Connor et al., 1967,1968 , and in our study two patients (Cases D2 and D3) were virtually asymptomatic at the time clinical cardiac abnormalities were first detected. Continued follow up of Case D4 will be of great interest since very early changes of endomyocardial fibrosis may be present, but are not yet diagnostic. The early recognition of the disease and refinement of diagnostic criteria are of obvious importance in the detection of aetiological factors. Prospective studies of populations at increased risk, such as in the Rwandan kindred with tropical splenomegaly syndrome, may prove of great value particularly if an infective agent is incriminated.

The concurrence of endomyocardial fibrosis, and tropical splenomegaly syndrome in five (and possibly seven) patients in this series is of considerable interest. This phenomenon may be explained by the increased susceptibility of Rwandan immigrants to both diseases (Shaper et al., 1968a). It is unfortunate that little information exists on the occurrence of endomyocardial fibrosis or tropical splenomegaly syndrome in Rwanda. The frequency of these diseases in such individuals who were born in Uganda, however, suggests that the disease was acquired in Uganda. Tropical splenomegaly syndrome has been attributed to an exaggerated immunological response to malarial infection (Stuiver et al., 1971), which may particularly affect immigrants from non-malarious areas to regions of malaria endemicity (such as Rwandans). A variety of autoantibodies, including anti-heart antibodies, has been detected in high frequency in sera from such individuals, and it has been postulated that autoimmune mechanisms may play a part in the pathogenesis of endomyocardial fibrosis (van der Geld et al., 1966; Shaper et al., 1968a). Other pathological observations tend to support this hypothesis (Connor et al., 1967, 1968). Continued studies of the relationship of endomyocardial fibrosis and tropical splenomegaly to malaria may shed further light on the immunopathological aspects.

It is of passing clinical interest that patients with tropical splenomegaly syndrome have been shown to have an expanded plasma volume (Richmond et al., 1967). The pathophysiology of this phenomenon is not understood, but should endomyocardial fibrosis develop in such a patient the increased circulatory load would be expected to hasten cardiac decompensation. In our experience with the tropical splenomegaly syndrome, the long-term administration of chloroquine and diuretics has been of considerable therapeutic value (Stuiver et al., 1971).

The observation of the familial occurrence of endomyocardial fibrosis reported in this study implies that genetic factors may be operative in the aetiology of the disease. The possibility of a transmitted infection is speculative. As yet no infective agent has been isolated in patients with endomyocardial fibrosis. Though the observation may be fortuitous in that the tribal incidence of endomyocardial fibrosis among Rwandans is high, hereditary factors, possibly immunological in nature, may contribute to the susceptibility to endomyocardial fibrosis.

We are grateful to the British Heart Foundation and the National and Grindlays Bank, Uganda, for their support of our studies on endomyocardial fibrosis. This work was supported in part by Contract No. P.H. 43-67-1343 from the National Cancer Institute, National Institutes of Health, Bethesda, Md.

Requests for reprints should be sent to Professor K. Somers, P.O. Box 7072, Kampala, Uganda.

\section{References}

Ball, J. D., Williams, A. W., and Davies, J. N. P. (1954). Lancet, 1, 1049. Cockshott, W. P., Saric, S., and Ikeme, A. C. (1967). Circulation, 35, 912 Connor, D. H., Somers, K., Hutt, M. S. R., Manion, W. C., and D'Arbela, P. G. (1967). American Heart Fournal, 74, 687 .
Connor, D. H., Somers, K., Hutt, M. S. R., Manion, W. C., and D'Arbela, P. G. (1968). American Heart fournal, 75, 107.

P. G. (1968). American Heart Fournal, 75, 107.
Crawford, M. A., Gale, M. M., Somers, K., and Hansen, I. L. (1970). British Fournal of Nutrition. 24, 393 .
B. A.

Davies, J. N. P. (1948). East African Medical Fournal, 25, 10.

Fowler, J. M., and Somers, K. (1968). Lancet, 1, 227.

Marsden, P. D., et al. (1965). British Medical fournal, 1, 89. 
Richmond, J., Donaldson, G. W. K., Williams, R., Hamilton, P. J. S., and Hutt, M. S. R. (1967). British fournal of Haematology, 13, 348. Shillingford, J. P., and Somers, K. (1961). British Heart fournal, 13, 177. Shaper, A. G., Kaplan, M. H., Mody, N. J., and McIntyre, P. A. (1968a). Lancet, 1, 1342.

Shaper, A. G., Hutt, M. S. R., and Coles, R. M. (1968b). British Heart fournal, 30, 391

Somers, K., and D'Arbela, P. G. (1964). Proceedings of the 3rd Asian Pacific Congress on Cardiology, Kyoto, 1,162 .

Somers, K., et al. (1968a). British Heart fournal, 30, 322
Somers, K., Brenton, D. P., and Sood, N. K. (1968b). British Heart Fournal, 30, 309 .

Somers, K., and Fowler, J. M. (1968). Cardiologia, 52, 25.

Somers, K., D'Arbela, P. G., and Patel, A. K. (1971). To be published. Stuiver, P. C., Ziegler, J. L., Wood, J. B., Morrow, R. H., and Hutt, M. S. R. (1971). British Medical fournal, 1, 426.

an der Geld, H., Peetoom, F., Somers, K., and Kanyerezi, B. R. (1966) Lancet, 2, 1210.

Ziegler, J. L., Banyikidde, S. K., Mody, N., Wood, J. B., and Hutt, M. S. R. (1970). East African Medical fournal, 47, 190.

\title{
Effect of Maternal Sickle-cell Trait on Perinatal Mortality
}

\author{
H. S. PLATT
}

British Medical fournal, 1971, 4, 334-336

\section{Summary}

Possession of the sickle-cell trait (Hb AS) by the African mother has been shown to be associated with a significant increase in perinatal mortality when there is anoxic stress. This observation should be taken into consideration in the management of labour of both the indigenous and immigrant mothers at risk. The findings do not influence the proposed explanations for the maintenance of high frequencies of the haemoglobin $S$ gene in areas of endemic malaria.

\section{Introduction}

The in-vitro and in-vivo formation of sickle-cells depends on a lowering of the oxygen tension (Hahn and Gillespie, 1927; Harris et al., 1956), but the erythrocytes of the sickle-cell trait (Hb AS) do not sickle under usual venous oxygen tensions, a level as low as $15 \mathrm{~mm} \mathrm{Hg}$ being required (Allison, 1956). Sickle-cell trait is associated only with serious life-threatening complications in the presence of unusual degrees of arterial oxygen desaturation. Clinical evidence of intravascular sickling in individuals with $\mathrm{Hb}$ AS was first noted in the second world war in Negro Service men flying in unpressurized aircraft (Smith and Conley, 1955), and the occurrence of sickling in other clinical situations has been reviewed (Levin, 1958; Necheles et al., 1969).

The incidence of the sickle-cell trait is variable in its distribution among Negroes, the highest rates occurring in areas of holoendemic malaria (Huehns and Shooter, 1965; Jonxis, 1965). Several mechanisms have been proposed to account for the maintenance of the high frequencies of the haemoglobin $S$ genes in malarious regions (Allison, 1954; Raper, 1955, 1959; Garlick, 1960; Motulsky, et al., 1966), including the proposition that there is increased fertility among females possessing the sicklecell trait (Edington, 1955; Livingstone, 1957; Delbrouck, 1958; Firschein, 1961).

In the present study the possibility of a selection factor operating against the sickle-cell trait was investigated.

\section{Material and Methods}

A perinatal mortality survey was conducted at University College Hospital, Ibadan, Nigeria, the survey period extending

Department of Clinical Pathology, University College Hospital, London WC1E 6AU

H. S. PLATT, M.D., B.SC., Senior Registrar from 1961 to 1964 covering 27 selected months (Platt, 1970). Necropsies were performed by one investigator on all perinatal deaths of infants over $500 \mathrm{~g}$ in weight occurring among booked and emergency admissions. A pathological classification for the cause of death was used based on that originally described by Bound et al. (1956), and subsequently adopted for the British National Perinatal Mortality Survey (Butler and Bonham, 1963).

An assessment of the clinicopathological associations was made in all cases of perinatal death, and details were obtained concurrently on all the "normal" deliveries occurring within the survey period.

Mothers were booked for delivery either because they had a previously poor obstetric history or because complications were deemed probable, the chief indication being potential mechanical difficulties in labour. A sickling test with $2^{\circ}{ }_{0}$ sodium metabisulphite was performed on all mothers making their first visit to the various antenatal screening clinics that were held at other hospitals. In the event of a positive sickling test further electrophoretic studies were performed and those possessing either $\mathrm{Hb} \mathrm{SC}$ or more rarely $\mathrm{Hb}$ SS were booked for delivery. In addition to normal obstetric care mothers received antimalarial drugs and folic acid during pregnancy.

The emergency admissions were either referred from other hospitals and domiciliary centres or came direct from homes in the town or outlying villages. Mothers would be admitted having a wide range of one or more obstetric or medical complications, though mechanical difficulties in labour, severe megaloblastic anaemia, and antepartum haemorrhage predominated. After admission the haemoglobin genotype was determined, care being taken to differentiate between the mother's true genotype and transfused blood that might have come from a $\mathrm{Hb}$ AS donor.

\section{Results}

In the survey period there were 435 singleton perinatal deaths and 4,148 singleton deliveries. Table I shows the rate per thousand (booked and emergency) deliveries of babies dying when the necropsy findings were predominantly those of anoxia. One in 20 of the booked and one in four of the emergency deliveries resulted in a perinatal death. Over half of all the singleton deaths were associated with anoxic stress occurring in the antepartum or intrapartum period; in the latter group birth trauma was apparent in some instances, and the risk ratio for an intrapartum death was one in 43 of all booked and one in seven of all emergency deliveries.

There was no selection of mothers with the sickle-cell trait for hospital delivery at U.C.H., Ibadan (Table II). The incidence of $\mathrm{Hb}$ AS among Yoruba blood donors and the booked mothers was identical and the same trend existed for emergency deliveries. 